\title{
THREE NEW RECORDS FOR TURKISH MYCOBIOTA
}

\author{
KELES, A. \\ Van Yüzüncü Yıl University, Education Faculty, Department of Science and Mathematics \\ Education, Van, Turkey \\ (e-mail: alikeles61@yahoo.com; phone: +90 43222517 01) \\ (Received $16^{\text {th }}$ Aug 2018; accepted $2^{\text {nd }}$ Jan 2019)
}

\begin{abstract}
The study was based on three basidiomycetous macroycete samples, collected from Trabzon and Erzincan provinces between 2013-2014, and aims to make a contribution to the mycomycota of Turkey by adding new records. The ecological characteristics of the fruit bodies were recorded and macro photographs of them were taken at their natural habitats. Then they were transferred to the fungarium and necessary investigations were carried out. By comparing the obtained macroscopic and microscopic measuremental data with those in literature, they were identified as Agaricus smithii Kerrigan, Coprinopsis goudensis (Uljé) Redhead, Vilgalys \& Moncalvo and Suillus tomentosus Singer. Tracing the current literature on macrofungi of Turkey, it is found that they were not reported from Turkey before. The taxa are described briefly and required data about their, habitat, ecology and geographical positions are provided together with macromorphological photographs and line drawings related to their micromorphologies.
\end{abstract}

Keywords: biodiversity, Basidiomycota, Erzincan, Trabzon

\section{Introduction}

Taxonomic studies on Turkish mycobiota had not a long history and has been accelerated especially in last three to four decades. Starting especially from 1970's numerous regional lists and new contributions were presented by many researchers, and the findings of these studies were prepared as checklists by Sesli and Denchev (2014) and Solak et al. (2015) with about 2,400 macrofungi species. Analysis of these checklist indicated that almost half of the current taxa were still reported from only 1 or two localities (Kaya, 2015). Contributory studies are still being carried out (Demirel et al., 2016; Keleş and Oruç, 2017; Uzun et al., 2017; Sadullahoğlu and Demirel, 2018; Sesli, 2018). But, considering the existence of about 15,000 macromycete taxa in Europe (Lukić, 2009) and the macrofungal diversity estimates of Mueller et al. (2007) regarding the plant/macrofungus ratios of temperate regions, we believe that, there is still much to be done to obtain the overall macrofungal data of Turkey (Kaya, 2009). Starting from this stand point, I usually perform field trips to observe and determine the macromycetes in our country. During such field trips three basidiomycetous macrofungi samples belonging to the families Agaricaceae, Psathyrellaceae and Suillaceae were collected from Erzincan and Trabzon provinces which fall in Irano-Turanean and EuroSiberian phytogeographical regions respectively within the holoarctic floral kingdom. As a result of necessary investigations, the samples were identified as Agaricus smithii Kerrigan, Coprinopsis goudensis (Uljé) Redhead, Vilgalys \& Moncalvo and Suillus tomentosus Singer. Tracing the current checklists macrofungi of Turkey (Sesli and Denchev, 2014; Solak et al., 2015) and latest contributions (Allı et al., 2017; Işık and Türkekul, 2017; Kaşık et al., 2017; Uzun et al., 2018; Uzun and Kaya, 2019), it is found that 35 species Agaricus L., 18 species Coprinopsis P. Karst., and 11 species of Suillus Gray. have been reported from Turkey, and the above three taxa were not recorded before. The study aims to make a contribution to the Turkish mycobiota. 


\section{Materials and methods}

Basidiomata of Coprinus goudensis were collected from İliç district of Erzincan province in 2013, and the basidiomata of Agaricus smithii and Suillus tomentosus were collected from Çamburnu district of Trabzon province in 2014 (Figure 1). During field studies, the ecological characteristics of the fruit bodies were recorded and macro photographs of them were taken at their natural habitats. Then the samples were transferred to the fungarium, dried in an air conditioned room, and prepared as fungarium materials. Dry materials were used for further investigations. Macroscopic measurements and micromorphologic investigations were carried out in fungarium. A Leica DM500 trinocular compound microscope was used for micromorphologic investigations. Microscopic features were portrayed with the CorelDRAW drawing program. The specimens were identified by comparing the obtained macroscopic and microscopic measuremental data with Smith and Thiers (1964), McKnight and McKnight (1987), Uljé and Bas (1993), Trudell and Ammirati (2009), Bessette et al. (2010), Desjardin et al. (2014), Gierczyk et al. (2014), Kuo and Methven (2014) and Kerrigan (2016). The samples are kept at the fungarium of Van Yüzüncü Y1l University in Van (VANF).

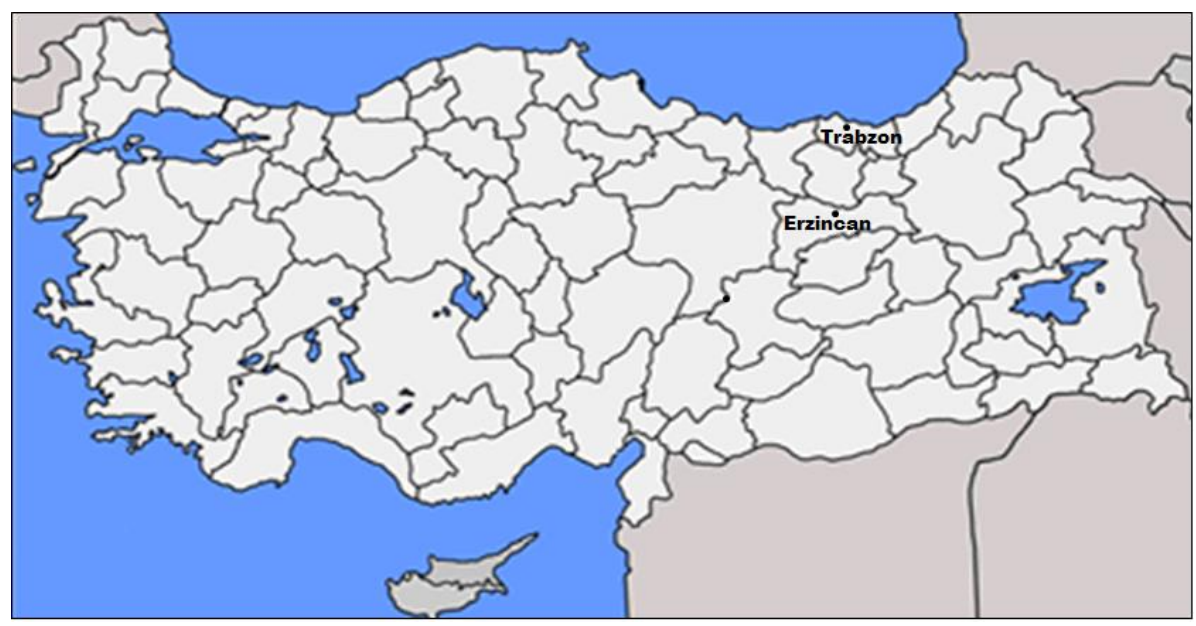

Figure 1. Collection locations of the determined macrofungi samples

\section{Results}

Brief descriptions, photograph of fruit bodies, and drawings of microcharacters are provided. The taxonomy of the taxa follows that of Kirk et al. (2008).

\section{Agaricus smithii Kerrigan}

\section{Macroscopic and microscopic features}

Pileus 8-12 cm wide, it grows from cylindrical to large convex. The edges not curved but sometimes can be slightly tasseled. The fibrillary is pale yellowish, brownish on a whitish ground color. Flesh thickness reaches up to $1.5 \mathrm{~cm}$ and does not change. Flavor and odour is like almonds. Lamellae not cramped, the color is pale, then turn into pinkish and becomes brown at maturity. Stipe $5-10 \times 2-3 \mathrm{~cm}$ hairless, whitish to yellowish brown. Spores 7.1-9.2 $\times$ 4.7-5.7 $\mu \mathrm{m}$ elliptical, smooth, dark brown. Basidia 19-24 × 8.7-10 $\mu \mathrm{m}$, clavate, 4-spored (Figure 2). 


\section{Specimen examined}

Trabzon, Çamburnu, north of Maritime Faculty, on soil under mixed trees, $40^{\circ} 55^{\prime} 378^{\prime \prime}$ N, 40¹2'613" E, 13 m., 21.10.2014, AK. 2941.

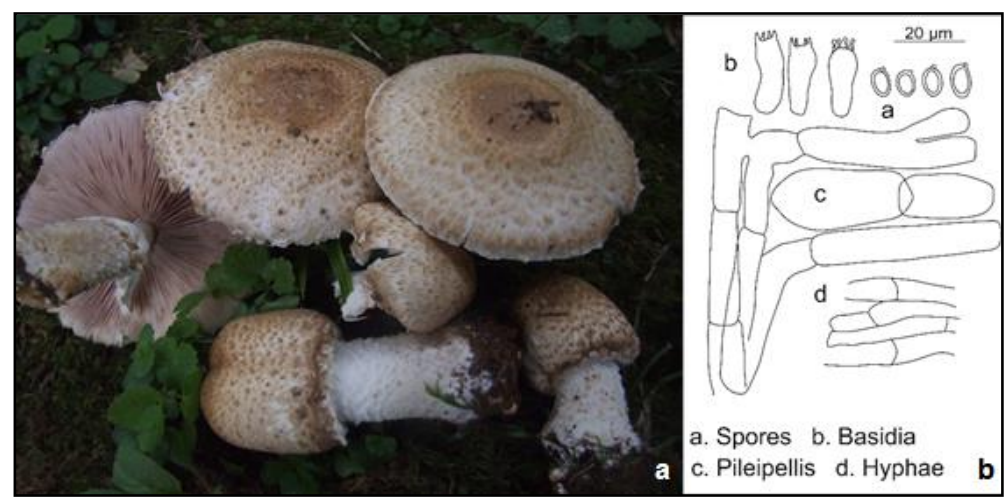

Figure 2. Agaricus smithii a) basidiocarps, b) microcharecters

\section{Coprinopsis goudensis (Uljé) Redhead, Vilgalys \& Moncalvo (Syn: Coprinus goudensis Uljé)}

\section{Macroscopic and microscopic features}

Pileus 1-2.2 $\mathrm{cm}$ when young, up to $3 \mathrm{~cm}$ when broadened, ellipsoid when young, then ovoid or conical, greyish-brown when young, then whitish brown, finally greyish blackbrown. Veil white, disintegrator in small, radial, hairy-fibrillose scales. Lamellae rather crowded, free, first white, then grey-brown to blackish. Stipe 2-5 $\times 0.1-0.2 \mathrm{~cm}$, white, greyish white, slightly white floccose, especially clavate at the base. Spores $6.8-11 \times 4.4-6.5 \mu \mathrm{m}$, ellipsoid or ovoid with rounded apex, sometimes oblong, rather pale red-brown and central, some with germpor. Basidia 22-38 × 7.5-10 $\mu \mathrm{m}$, 4-spored. Cheilocystidia subglobose, ovoid, $33-70 \times 25-52 \mu \mathrm{m}$. Pleurocystidia cylindrical to oblong, 50-105 $\times 32-55 \mu \mathrm{m}$. Elements of veil up to $13 \mu \mathrm{m}$ widen and diverticulate (Figure 3).

\section{Specimen examined}

Erzincan, İliç, Kuruçay village, on decaying wood remnants, Erzincan, 39³6'744" N, 38³1'147" E, 999 m, 08.05.2013, AK. 2066.

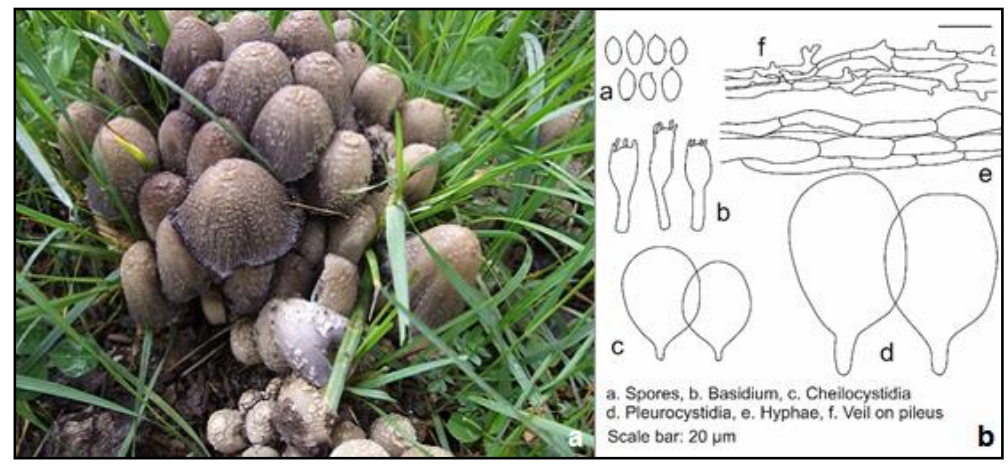

Figure 3. Coprinopsis goudensis a) basidiocarps, b) microcharecters 


\section{Suillus tomentosus Singer}

\section{Macroscopic and microscopic features}

Pileus 6-12 cm wide, convex when young, edges curved when matured, the curve disappear when moist, the surface sticky, color vary from pale yellow color to dirty skin color, stain characteristically vary from gray to olive greenish-gray. Flesh thick, soft, white to pale yellow, turns blue when damaged. Hymenophore tubes up to $1.5 \mathrm{~cm}$ long, pores approximately $1 \mathrm{~mm}$ thick, angled pale brown, when matures become dark yellow. Stipe $5-10 \times 1.5-3 \mathrm{~cm}$ hard and sticky to the floor. While the upper part varies from yellowish to orange, the lower part varies from slightly reddish to brown. Spores $8-12 \times 3-4.5 \mu \mathrm{m}$, narrow, ellipsoid, smooth, thick-walled, dark olive greenish-brown (Figure 4).

\section{Specimen examined}

Trabzon, Çamburnu, near Forestry Directorate Hotel, among needle-litter under pine trees, 4055'379" N, 40²12'790" E, 93 m., 29.10.2014, AK. 2962.

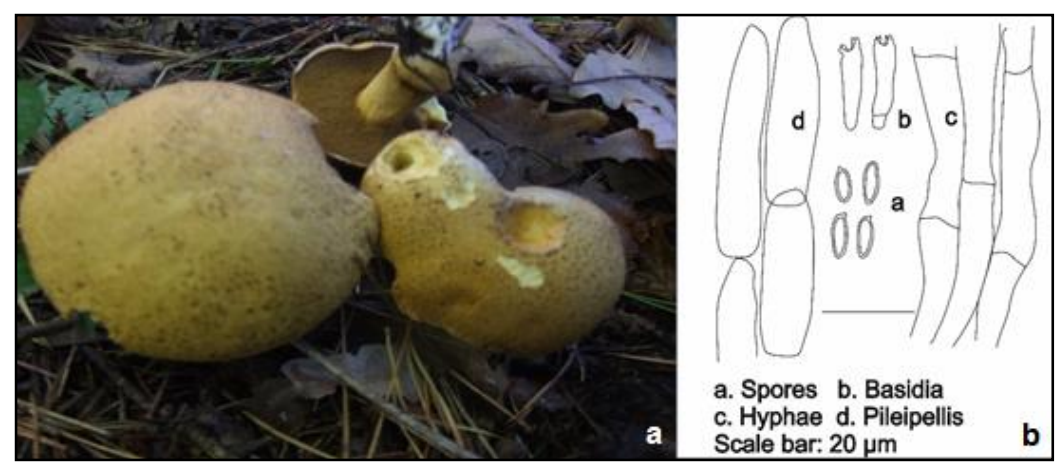

Figure 4. Suillus tomentosus a) basidiocarps, b) microcharecters

\section{Discussion}

With this study, the basidiomycete taxa Agaricus smithii, Coprinopsis goudensis, and Suillus tomontosus were given as new records from Turkey. The determined characteristics of the investigated samples conforms those given in literature.

Agaricus smithii is easily determined by the egg-shaped pileus when young, tawny to gold or orange cap colors, long stipe and amygdale odor. Young specimens of this species have similar morphology with A. sylvicola (Vittad.) Peck. But the appressedfibrillose to fibrillose-scaly mature cap differs it from $A$. sylvilcola which have a subglabrous to silky fibrillose cap at maturity (Desjardin et al., 2014). Shorter spores of A. sylvicola is another distinguishing feature between the two species (Kerrigan, 1986).

Coprinopsis goudensis can easily be recognized by the ellipsoid spores which in average are less than $10 \mu \mathrm{m}$ long, having an average quotient of 1.6 or more, and the lignicolous habitat (Gierczyk et al., 2014). In terms of morphological similarity this species can be compared with $C$. luteocephala (Watling) Redhead, Vilgalys \& Moncalvo, C. neotropica (Redhead \& Pegler) Redhead, Vilgalys \& Moncalvo, $C$. stangliana (Enderle, Bender \& Gröger) Redhead, Vilgalys \& Moncalvo and $C$. urticicola (Berk. \& Broome) Redhead, Vilgalys \& Moncalvo. Among them $C$. luteocephala differs with yellow veil, larger spore and substrate (dung), C neotropica 
differs with smaller and much broader spores, and trophica-l habitat, C. stangliana differs with much larger basidiocarps and spores, and habitat (soil), and C. urticicola differs in much smaller spores and basidiocarps (Uljé and Bas, 1993).

Suillus tomentosus is a very common species and is morphologically similar to $S$. americanıs, $S$. hirtellus, $S$. pictus and $S$. subaureus, but any of the latter species present blue-stairing reactions when cut or injured (Lincoff, 1981; McKnight and MacKnight, 1987; Trudell and Ammirati, 2009). Since all parts this edible species stains blue when bruised or cut, one should be sure wlihe distinguishing it from other blue-staining suillus species (McKnight and MacKnight, 1987).

\section{Conclusion}

Agaricus smithii, Coprinopsis goudensis, and Suillus tomontosus were given as new records from Turkey, increasing the current taxa numbers of the genera Agaricus, Coprinopsis and Suillus, in Turkey, to 36, 19 and 12, respectively.

\section{REFERENCES}

[1] Allı, H., Çöl, B., Şen, İ. (2017): Macrofungi biodiversity of Kütahya (Turkey) province. Biological Diversity and Conservation 10(1): 133-143.

[2] Bessette, A. E., Roody, W. C., Bessette, A. R. (2010): North American Boletes, A Color Guide to the Fleshy Pored Mushrooms. - Syracuse: Syracuse University Press.

[3] Demirel, K., Uzun, Y., Keleş, A., Akçay, M. E., Acar, İ. (2016): Macrofungi of KaragölSahara National Park (Şavşat-Artvin/Turkey). - Biological Diversity and Conservation 10(2): 32-40.

[4] Desjardin, D. E., Wood, M. G., Stevens, F. A. (2014): California Mushrooms, The Comprehensive Identification Guide. - London: Timber Press.

[5] Gierczyk, B., Kujawa, A., Szczepkowski, A. (2014): New to Poland species of the broadly defined genus Coprinus (Basidiomycota, Agaricomycotina). - Acta Mycol 49(2): 159-188.

[6] Iş1k, H., Türkekul, İ. (2017): A new record for Turkish mycota from Akdağmadeni (Yozgat) province: Russula decolorans (Fr.). - Anatolian Journal of Botany 1(1): 1-3.

[7] Kaş1k, G., Aktaş, S., Alkan, S., Öztürk, C. (2017): Additions to the Macrofungi of Selçuk University Alaeddin Keykubat Campus (Konya). - The Journal of Fungus 8(2): 129-136.

[8] Kaya, A. (2009): Macrofungal diversity of Adiyaman Province (Turkey). - Mycotaxon 110: 43-46.

[9] Kaya, A. (2015): Contributions to the macrofungal diversity of Atatürk Dam Lake basin. - Turk J Bot 39: 162-172.

[10] Keleş, A., Oruç, Y. (2017): Leucocoprinus brebissonii (Godey) Locq, A New Record for Turkish Mycobiota. - Anatolian Journal of Botany 1(2): 49-51.

[11] Kerrigan, R. W. (2016): Agaricus of North America. - New York Botanical Garden, New York, USA.

[12] Kirk, P. F., Cannon, P. F., Minter, D. W., Stalpers, J. A. (2008): Dictionary of the Fungi. 10th ed. - Wallingford, UK: CAB International.

[13] Kuo, M., Methven, S. A. (2014): Mushrooms of the Midwest. - University of Illinois Press. Urbana, Chicago and Springfield. USA.

[14] Lincoff, G. H. (1981): Field Guide to North American Mushrooms. - New York: Alfred A. Knopf.

[15] Lukić, N. (2009): The distribution and diversity of Boletus genus in central Serbia. Kragujevac J. Sci. 31: 59-68. 
[16] McKnight, K. H., McKnight, V. B. (1987): A Field Guied to Mushrooms of North America. - New York: Houghton Mifflin Co.

[17] Mueller, G. M., Schmit, J. P., Leacock, P. R., Buyck, B., Cifuentes, J., Desjardin, D. E., Halling, R. E., Hjortstam, K., Iturriaga, T., Larsson, K. H., Lodge, D. J., May, T. W., Minter, D., Rajchenberg, M., Redhead, S. A., Ryvarden, L., Trappe, J. M., Watling, R., $\mathrm{Wu}$, Q. (2007): Global diversity and distribution of macrofungi. - Biodiversity and Conservation 16: 37-48.

[18] Sadullahoğlu, C., Demirel, K. (2018): Flammulina fennae Bas, A New Record from Karz Mountain (Bitlis). - Anatolian Journal of Botany 2(1): 19-21.

[19] Sesli, E. (2018): Cortinarius ve Lyophyllum Cinslerine Ait Yeni Kayitlar. - Mantar Dergisi 9(1): 18-23.

[20] Sesli, E., Denchev, C. M. (2014): Checklists of the myxomycetes, larger ascomycetes, and larger basidiomycetes in Turkey. 6th edn. Mycotaxon. - Checklists Online (http://www.mycotaxon.com/resources/checklists/sesli-v106-checklist.pdf): 1-136.

[21] Smith, A. H., Thiers, H. D. (1964): A Contribution Toward a monograph of North American Species of Suillus. - Ann Arbor, Michigan, USA. 85.

[22] Solak, M. H., Işıloğlu, M., Kalmış, E., Allı, H. (2015): Macrofungi of Turkey, Checklist, Volume- II. - Üniversiteliler Ofset, Bornova, İzmir.

[23] Trudell, S., Ammirati, J. (2009): Mushrooms of the Pacific Northwest. - Oregon: Timber Press.

[24] Uljé, C. B., Bas, C. (1993): Some new species of Coprinus from the Netherlands. Persoonia 15(3): 357-368.

[25] Uzun, Y., Acar, İ., Akçay, M. E., Kaya, A. (2017): Contributions to the macrofungi of Bingöl, Turkey. - Turk J Bot 41: 516-534.

[26] Uzun, Y., Kaya, A. (2019): Elaphomyces granulatus, A New Hypogeous Ascomycete Record for Turkey. - KSU J. Agric Nat 22(1): 85-88.

[27] Uzun, Y., Yakar, S., Karacan, İ. H., Kaya, A. (2018): New additions to the Turkish Pezizales. - Turk J Bot 42: 335-345. 